Article

\title{
Fatigue Strength Assessment of Steel Rollers: On the Reliability of the Strain Energy Density Approach on Real Components
}

\author{
Francesco Chebat ${ }^{1}$, Mirco Peron ${ }^{2, *}$, Luigi Mario Viespoli ${ }^{2}$, Torgeir Welo ${ }^{2}$ and Filippo Berto ${ }^{2}$ \\ 1 Rulli Rulmeca S.P.A, 24011 Almè (BG), Italy; fchebat@rulmeca.com \\ 2 Department of Industrial and Mechanical Engineering, Norwegian University of Science and Technology, \\ Richard Birkelands vei 2b, 7034 Trondheim, Norway; luigimv@stud.ntnu.no (L.M.V.); \\ torgeir.welo@ntnu.no (T.W.); filippo.berto@ntnu.no (F.B.) \\ * Correspondence: mirco.peron@ntnu.no; Tel.: +47-485001574
}

Received: 7 June 2018; Accepted: 18 June 2018; Published: 21 June 2018

\begin{abstract}
Welded joints are one of the most widely applied methods to join different steel components. However, they introduce stress concentrators that are commonly known to reduce the fatigue strength of structures. Several methods have been developed to assess the fatigue behavior of welded components, such as the Notch Stress Intensity Factors (NSIFs) approach. However, this approach has been reported to be geometry dependent, and does not allow for a direct comparison of failures occurring at the weld toes with those occurring at the weld roots. This drawback has been overcame by considering the value of the strain energy density (SED) range averaged in a control volume ahead of the notch tip. More than 900 fatigue data of welded joints have been summarized within a single scatter band $\Delta \mathrm{W}-\mathrm{N}$ (strain energy range-umber of cycles to failure) using this approach. The reliability of the just mentioned scatter band in summarizing the fatigue data of real components such as steel welded rollers produced by Rulmeca is herein evaluated. The results prove the reliability of the SED approach to assess the fatigue behavior of welded rollers, paving the way to its diffusion in assessing real components.
\end{abstract}

Keywords: welded joints; fatigue strength; strain energy density; rollers; notch

\section{Introduction}

Welding procedures have allowed the simple realization of many complex structural connections in several different applications, such as bridges, cranes, offshore structures, and buildings [1]. Besides the optimization of the process parameters [2-4], researchers have focused on the fatigue behavior of welded components. All the aforementioned applications are in fact subjected to repetitive loading and hence the fatigue of welded structures has become one of the greatest matters of concern [5]. Welds represent local regions of higher stresses (i.e., stress concentrators) and fatigue failure is widely known to be sensitive to local peak stresses. Thus, over the years, several methods have been developed to assess the fatigue behavior of welds, and among these the Notch Stress Intensity Factor (NSIF) approach is worth mentioning [6-8]. In fact, since experimental observations have revealed that the most used welding procedures, such as arc and laser welding, are characterized by a very small weld toe radius, it is acceptable to model it as a sharp notch and the fatigue behavior can thus be correlated to the NSIFs $[9,10]$. Fatigue life can be divided into two different phases; i.e., nucleation and growth of cracks-and NSIFs were found to be able to predict either the initiation phase or the whole fatigue life [11-14]. This holds when the majority of the propagation phase has been spent within the region governed by the stress singularity. Several studies proved this behavior. Lassen demonstrated that in transverse, non-load-carrying joints manufactured via different welding procedures the nucleation of 
a $0.1 \mathrm{~mm}$ long crack required up to $40 \%$ of the whole fatigue life [15]. In addition, Singh et al. reported that in load-carrying AISI 304L fillet joints up to $70 \%$ of the fatigue life was spent propagating the original lack of a penetration crack of $0.5 \mathrm{~mm}[16,17]$. However, the results are highly dependent of the on the stress distribution ahead of the point of singularity and, since time consuming FE analyses are required, this has limited the diffusion of the NSIFs approach in the assessment of real structures. Furthermore, the main limitation of this method consists in its geometry dependency. Its unit depends in fact on the notch opening angle according to Williams' formulations [18]. Different notch geometries are not thus comparable but ad-hoc material properties are required for each geometry. A breakthrough in the fatigue assessment of welded joints is represented by the strain energy density (SED) method, capable of overcoming all the limitations of the NSIFs approach [19]. The SED is evaluated averaging the range value of the strain energy in a cylindrical volume sector of radius $R_{c}$ centered at the notch tip. According to this approach, fatigue failure occurs then this scalar quantity reaches its critical value $\Delta W_{c}$. Both the radius $R_{c}$ and the critical energy range $\Delta W_{c}$. depend only on material properties [11] and shall be assumed to be independent of the load mode. Using this approach, Livieri and Lazzarin [20] summarized more than 600 experimental data obtained from different welded joints within a single narrow SED scatter-band. Failures occurred either at the weld root or at the weld toe. This work has then been extended by Berto and Lazzarin [21], including hollow section joints, and now more than 900 fatigue data are summarized in a single scatter band as depicted in Figure 1.

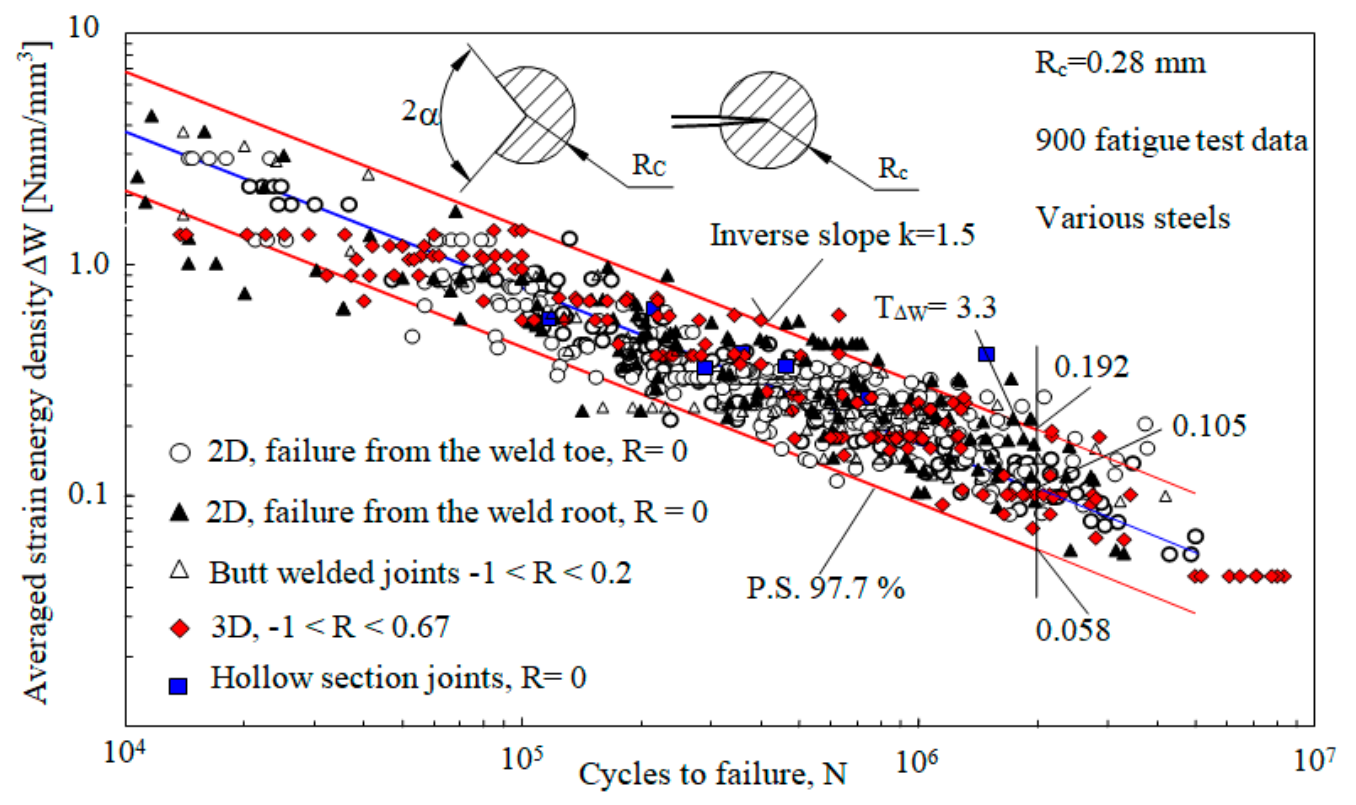

Figure 1. Fatigue behavior of welded joints as a function of the averaged local strain energy density range $\Delta W ; R$ is the nominal load ratio.

Moreover, the SED approach has been also reported to be a reliable tool in multi-axial fatigue assessment. Berto and Lazzarin [22] in fact resumed several experimental fatigue data obtained for structural steel within a single scatter band, drawn according to the following two assumptions: First, the critical value of strain energy density is considered to be independent from the type of loading in the high-cycle fatigue regime, and its value at $2 \times 10^{6}$ cycles has thus been imposed equal to that obtained for welded joints under uniaxial loading; a slope equal to $5 / 2$ as suggested in Ref. [23] has been used. The approach has then been successfully applied to either the tensile or fatigue assessment of several notched materials, from metals [24-32] to polymers [33-35] and ceramics [36,37].

Recently, the SED approach was also preliminarily applied to the fatigue assessment of real components, such as rollers (Figure 2) produced by Rulmeca [38]. Besides surface pitting due to contact fatigue $[39,40]$, rollers are in fact affected by fatigue failures at the weld root. The bearing housings 
of the rollers are joint to the tube body by means of welding procedures. Although the connection between the bearing housings and the tube body is fundamental in preventing any imbalance in the roller, it is responsible to the fatigue failure of the rollers due to the lack of penetration at the weld root.

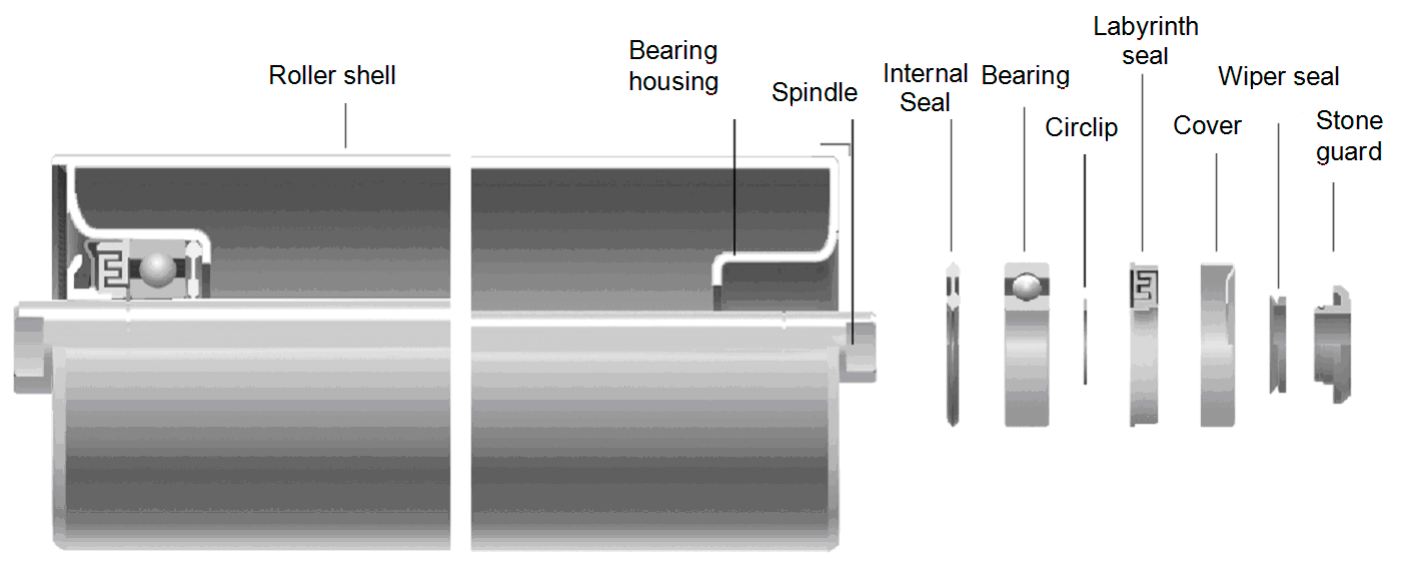

Figure 2. Typical roller assembly.

This work aims to further analyze the problem of fatigue failure at the weld root and to assess the reliability of the SED scatter band reported in Figure 1 in their assessment. Hence, firstly, new fatigue data sets have been obtained for three different roller types; i.e., PSV2, PSV4 and PSV5—and each roller type was characterized by different dimensions. Then, the new fatigue data together with those reported in Ref. [38] were analyzed in terms of SED, and they have been shown to be satisfactorily resumed by the scatter band obtained in Ref. [21]. This represents a breakthrough in the fatigue design of rollers, and in general of welded structures, since the SED scatter band reported in Figure 1 can be reliably used to predict the fatigue behavior of real components, whether they fail at the weld root or at the weld toe.

\section{A Brief Description of the Strain Energy Density Approach}

Considering the SED criterion [19] statements for dynamic loadings, fatigue failure occurs when the strain energy range $\Delta \bar{W}$ averaged in a control volume of radius $R_{c}$ ahead of the crack tip reaches its critical value $\Delta W_{c}$. Simple analytical formulations have been obtained in Ref. [19] for the assessment of the critical value of the strain energy density range $\Delta W_{\mathcal{c}}$ (Equation (1)) and of the critical radius $R_{c}$ (Equation (2)):

$$
\begin{gathered}
\Delta W_{C}=\frac{\Delta \sigma_{A}^{2}}{2 E} \\
R_{C}=\left(\frac{\sqrt{2 e_{1}} \Delta K_{1 A}}{\Delta \sigma_{A}}\right)^{\frac{1}{1-\lambda_{1}}}
\end{gathered}
$$

where $\Delta \sigma_{A}$ is the fatigue limit of the material without geometric singularities, $E$ is the Young's modulus of the material, $\lambda_{1}$ is Williams' eigenvalue for mode 1 [18], $\Delta K_{1 A}^{N}$ is the amplitude of the Notch Stress Intensity Factors (NSIF) fatigue threshold, and $e_{1}$ is a parameter dependent either on geometrical parameters (the notch opening angle $2 \alpha$ ) or on material properties (the Poisson's ratio $v$ ). The reader should refer to Ref. [19] for $e_{1}$ formulation. Dealing with rollers, the control volume is a circle centered at the weld root tip (blue circle in Figure 3), and its radius, as well as the critical strain energy density range value, is only dependent on the material [11]. 


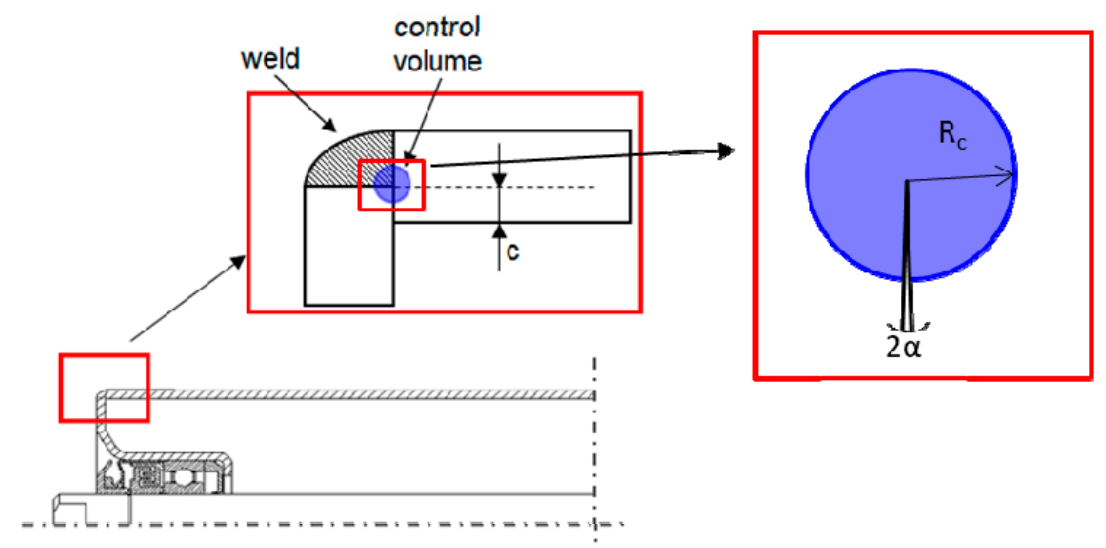

Figure 3. Schematic representation of the weld root, characterized by a weld root length " $c$ ", and the control volume of the strain energy density (SED) approach (blue circle).

The value of the critical radius has been obtained by leveraging on previously published data either for failures at the weld root or at the weld toe. Concerning the former, considering the value of $211 \mathrm{MPa} \mathrm{mm}{ }^{0.326}$ for the amplitude of the Notch Stress Intensity Factors $\Delta K_{1 A}^{N}$ obtained by Livieri and Lazzarin [41] for the transverse non-load carrying fillet welded joints, and that of $153 \mathrm{MPa}$ for the fatigue strength $\Delta \sigma_{A}$ of butt ground welds obtained by Taylor at al. [42], the critical value $R_{c}$ for steel welded joints corresponds to $0.28 \mathrm{~mm}$. Dealing with the case of failure to occur at the weld root, instead, considering $\Delta K_{1 A}^{N}=180 \mathrm{MPa} \mathrm{mm}^{0.5}$, Equation (2) gives a critical value of the radius equal to $0.36 \mathrm{~mm}$. However, being on the safe side, an $R_{c}$ value of $0.28 \mathrm{~mm}$ has been used in this work also for failures occurring at the weld roots.

\section{Geometry}

In this report rollers belonging to the series PSV were studied. Representing the state of the art of Rulmeca's production [34], these rollers are widely required for conveyors in applications characterized by high working load and by the need to convey large lump size materials. The main components of the roller are reported in Figure 2 and their functions are widely described in Ref. [38]. Among them, the feature investigated in this work is the joint between the roller shell (tube) and the bearing housing, where the failure occurs. Joining these two features optimizes the roller performance, avoiding any imbalance in the rollers and allowing their use at the highest speeds. However, although weldment is of utmost importance for a proper roller operation, it represents the weakest point of the structure considering fatigue behavior, since the lack of penetration at the weld root (Figure 4) leads to the final failure of the roller (Figure $4 b, c$ ).

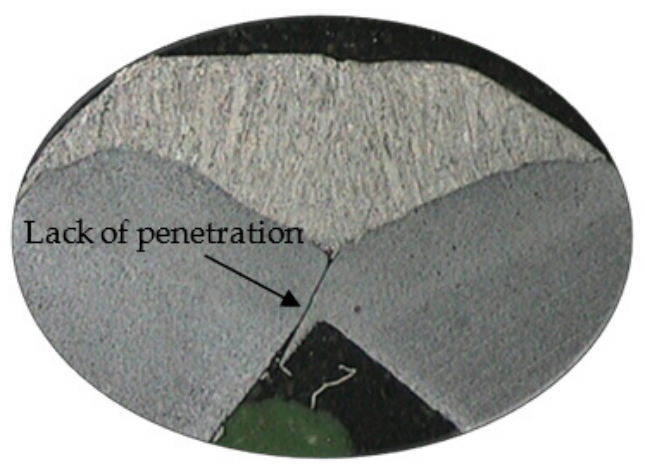

(a)

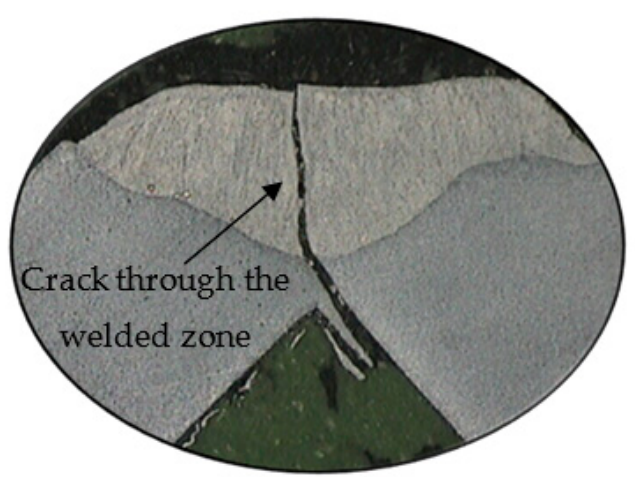

(b)

Figure 4. Cont. 


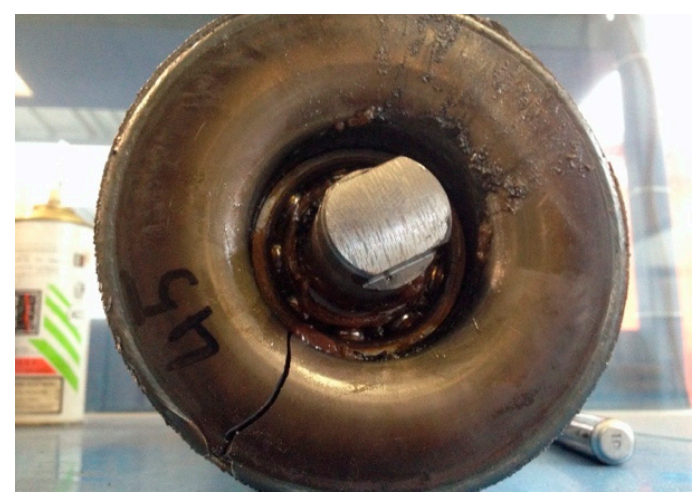

(c)

Figure 4. Lack of penetration at the weld root (a), a detail of the crack through the welded zone (b) and typical roller failure $(c)$.

The length of the lack of penetration, indicated as $c$ in Figure 3, has been determined carrying out micrographic analyses on the welded rollers, resulting in a value of $c$ in the range between 0.6 and $1.0 \mathrm{~mm}$. As reported in Ref. [38], the SED value is slightly affected by a variation of c in this range, and thus the length $c=1 \mathrm{~mm}$ is set in all the analyses.

The rollers tested in this work belong to three different types of rollers; i.e., PSV2, PSV4 and PSV5. The geometrical parameters are listed in Table 1 in addition to the rollers tested in Ref. [38]; i.e., PSV4 133315 and PSV4 159 530. See Figure 5 for an explanation of the meaning of the geometrical details.

Table 1. Geometrical parameters of the rollers considered in the present investigation and in Ref. [38] $\left(^{*}\right)$.

\begin{tabular}{ccccc}
\hline Model Name & $\begin{array}{c}\text { Length of the } \\
\text { Roller [mm] }\end{array}$ & $\begin{array}{c}\text { Diameter of the } \\
\text { Roller [mm] }\end{array}$ & $\begin{array}{c}\text { Tube Thickness } \\
\text { [mm] }\end{array}$ & Bearing Type \\
\hline PSV2 133 315 & 315 & 133 & 4 & 6205 \\
PSV2 133 600 & 600 & 133 & 4 & 6205 \\
PSV2 159 380 & 380 & 159 & 4.5 & 6205 \\
PSV2 159 600 & 600 & 159 & 4.5 & 6205 \\
PSV4 133 315* & 315 & 133 & 4 & 6206 \\
PSV4 159 530* & 530 & 159 & 4.5 & 6206 \\
PSV5 133 315 & 315 & 133 & 4.5 & 6306 \\
PSV5 159 530 & 530 & 159 & 6306 \\
\hline
\end{tabular}

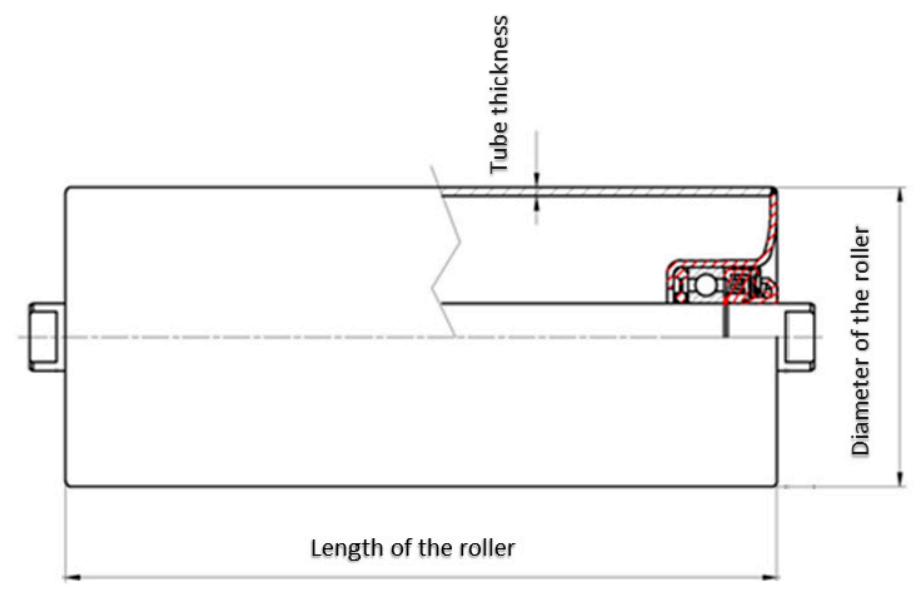

Figure 5. Geometry of the rollers. 


\section{Results}

Seven different roller geometries have been tested under fatigue; i.e., PSV2 133 315, PSV2, PSV2 133 600, PSV2 159 380, PSV2 159 600, PSV4 159 530, PSV5 133 315, PSV5 159 530. The test system mimicking the in-service conditions of the rollers was developed by the authors. An external counter-roll presses the tested roller, which rotates with a constant speed, with a constant pressure, applying the load. Further details about the test system can be found in Ref. [38]. The fatigue results for each geometry are reported in Tables 2-8. In Table 6 the fatigue results obtained in Ref. [38] are also reported. In addition, in Table 9 the experimental data obtained in Ref. [38] for PSV4 133315 are resumed.

Table 2. Fatigue data for the roller PSV2 133315.

\begin{tabular}{rccccc}
\hline Samples & & Load [Kg] & RPM & Cycles & SED [M]/mm $\left.\mathbf{m}^{\mathbf{3}}\right]$ \\
\hline PSV2 133 315 & 1 & 541 & 545 & $2,151,388$ & 0.101 \\
& 2 & 512 & 545 & $1,343,313$ & 0.091 \\
& 3 & 466 & 545 & $5,328,121$ & 0.075 \\
& 4 & 457 & 545 & $2,440,852$ & 0.072 \\
& 5 & 451 & 545 & $11,468,429$ & 0.071 \\
& 6 & 420 & 545 & $10,198,955$ & 0.061 \\
& 7 & 380 & 591 & $8,620,179$ & 0.050 \\
\hline
\end{tabular}

Table 3. Fatigue data for the roller PSV2 133600.

\begin{tabular}{rccccc}
\hline Samples & & Load [Kg] & RPM & Cycles & SED [MJ/mm ${ }^{3}$ ] \\
\hline PSV2 133 600 & 1 & 545 & 653 & $6,478,432$ & 0.091 \\
& 2 & 531 & 653 & $6,373,931$ & 0.086 \\
& 3 & 522 & 648 & $10,132,740$ & 0.083 \\
& 4 & 484 & 641 & $10,699,396$ & 0.072 \\
& 5 & 461 & 641 & $10,722,269$ & 0.065 \\
& 6 & 395 & 493 & $10,075,994$ & 0.048 \\
\hline
\end{tabular}

Table 4. Fatigue data for the roller PSV2 159380.

\begin{tabular}{cccccc}
\hline Samples & & Load $[\mathrm{Kg}]$ & RPM & Cycles & SED $\left[\mathbf{M J} / \mathbf{m m}^{3}\right.$ ] \\
\hline PSV2 159 380 & 1 & 1231 & 534 & 259,463 & 0.517 \\
& 2 & 899 & 534 & 416,956 & 0.276 \\
& 3 & 856 & 534 & 695,104 & 0.250 \\
& 4 & 814 & 534 & 534,408 & 0.226 \\
& 5 & 745 & 534 & 557,365 & 0.189 \\
& 6 & 540 & 534 & $1,556,243$ & 0.099 \\
& 7 & 448 & 534 & $10,752,532$ & 0.068 \\
& 8 & 431 & 534 & $5,451,923$ & 0.063 \\
& 9 & 397 & 534 & $7,611,444$ & 0.054 \\
& 10 & 344 & 534 & $5,958,036$ & 0.040 \\
& 11 & 298 & 534 & $10,612,449$ & 0.030 \\
& 12 & 238 & 534 & $14,382,785$ & 0.019 \\
\hline
\end{tabular}


Table 5. Fatigue data for the roller PSV2 159600.

\begin{tabular}{rccccc}
\hline Samples & & Load [Kg] & RPM & Cycles & SED [MJ/mm $\mathbf{m m}^{3}$ \\
\hline PSV2 159 600 & 1 & 561 & 534 & $2,119,258$ & 0.101 \\
& 2 & 527 & 534 & $3,983,769$ & 0.089 \\
& 3 & 502 & 534 & $2,452,618$ & 0.081 \\
& 4 & 471 & 534 & $2,809,780$ & 0.071 \\
& 5 & 424 & 534 & $10,434,390$ & 0.058 \\
& 6 & 402 & 534 & $10,224,224$ & 0.052 \\
& 7 & 373 & 534 & $11,459,075$ & 0.045 \\
& 8 & 351 & 534 & $14,488,277$ & 0.039 \\
& 9 & 324 & 534 & $10,663,603$ & 0.034 \\
& 10 & 302 & 544 & $12,563,405$ & 0.029 \\
& 11 & 283 & 544 & $10,665,627$ & 0.026 \\
12 & 254 & 544 & $10,159,436$ & 0.021 \\
\hline
\end{tabular}

Table 6. Fatigue data for the roller PSV4 159530.

\begin{tabular}{cccccc}
\hline Samples & & Load $[\mathbf{K g}]$ & RPM & Cycles & SED [MJ/mm $\left.\mathbf{m}^{3}\right]$ \\
\hline PSV4 159 530 & $1^{*}$ & 1262 & 541 & 363,234 & 0.278 \\
& $2^{*}$ & 1251 & 541 & 370,432 & 0.274 \\
& $3^{*}$ & 994 & 541 & 677,279 & 0.173 \\
& $4^{*}$ & 992 & 541 & 747,548 & 0.172 \\
& $5^{*}$ & 991 & 541 & 598,390 & 0.172 \\
& $6^{*}$ & 990 & 541 & 619,344 & 0.171 \\
& 7 & 768 & 545 & $6,140,003$ & 0.103 \\
8 & 715 & 545 & $3,352,651$ & 0.089 \\
& $9^{*}$ & 708 & 545 & $2,749,333$ & 0.088 \\
10 & 681 & 545 & $15,139,928$ & 0.081 \\
11 & 621 & 545 & $5,433,742$ & 0.067 \\
12 & 585 & 545 & $10,065,572$ & 0.060 \\
13 & 536 & 545 & $10,791,789$ & 0.050 \\
14 & 523 & 545 & $9,962,179$ & 0.048 \\
$*$ & & 545 & $10,690,499$ & 0.040 \\
15 & 480 & 545 & $11,909,310$ & 0.036 \\
16 & 456 & 545 & $11,221,894$ & 0.032 \\
17 & 428 & 545 & $15,489,417$ & 0.028 \\
18 & 401 & 545 & $11,608,328$ & 0.026 \\
19 & 388 & 545 & $10,967,692$ & 0.020 \\
\hline 20 & 340 &
\end{tabular}

Data characterized by * were already presented in Ref. [38].

The fatigue data reported in Tables 2-9 have been analyzed in terms of the SED range by means of FE analyses (details on FE models can be found in Ref. [38]). The results have been compared with the scatter band presented in Ref. [21]. It is worth mentioning that the just mentioned scatter band has been obtained by mostly considering welded joints that fail at the weld toes (Figure 6). It can be seen that the scatter band previously obtained allows reliable predictions of fatigue strength of different roller geometries that fail at the weld root. Therefore, the aforementioned scatter band has revealed to be a reliable tool for the assessment of the fatigue failure of the welded joints regardless of the location of the failure. 
Table 7. Fatigue data for the roller PSV5 133315.

\begin{tabular}{cccccc}
\hline Samples & & Load [Kg] & RPM & Cycles & SED [MJ/mm $\mathbf{m}^{\mathbf{3}}$ \\
\hline PSV5 133 315 & 1 & 1251 & 643 & 306,221 & 0.230 \\
& 2 & 1245 & 643 & 605,933 & 0.228 \\
& 3 & 1200 & 643 & $1,399,867$ & 0.212 \\
& 4 & 815 & 638 & 910,164 & 0.098 \\
& 5 & 807 & 638 & 231,3360 & 0.096 \\
& 6 & 795 & 638 & $2,089,012$ & 0.093 \\
& 7 & 776 & 638 & $4,078,198$ & 0.089 \\
& 8 & 752 & 638 & $10,913,677$ & 0.083 \\
& 9 & 713 & 638 & $5,059,160$ & 0.075 \\
& 10 & 695 & 638 & $12,802,353$ & 0.071 \\
& 11 & 678 & 638 & $3,863,892$ & 0.068 \\
& 12 & 657 & 643 & $14,832,967$ & 0.064 \\
& 13 & 593 & 641 & $4,625,783$ & 0.052 \\
14 & 556 & 641 & $12,891,317$ & 0.045 \\
& 15 & 508 & 641 & $11,974,027$ & 0.038 \\
\hline
\end{tabular}

Table 8. Fatigue data for the roller PSV5 159530.

\begin{tabular}{cccccc}
\hline Samples & & Load $[\mathrm{Kg}]$ & RPM & Cycles & SED $\left[\mathbf{M J} / \mathbf{m m}^{3}\right.$ ] \\
\hline PSV5 159 530 & 1 & 919 & 543 & $1,500,112$ & 0.124 \\
& 2 & 883 & 543 & $1,368,180$ & 0.114 \\
& 3 & 832 & 543 & $2,351,632$ & 0.101 \\
& 4 & 782 & 543 & $3,250,568$ & 0.090 \\
& 5 & 736 & 543 & $3,463,929$ & 0.079 \\
& 6 & 727 & 543 & $3,203,478$ & 0.077 \\
& 7 & 710 & 543 & $4,187,825$ & 0.074 \\
& 8 & 698 & 543 & $3,082,748$ & 0.071 \\
& 9 & 660 & 543 & $3,361,271$ & 0.064 \\
& 10 & 659 & 543 & $3,086,549$ & 0.064 \\
& 11 & 628 & 543 & $2,994,251$ & 0.058 \\
& 12 & 615 & 543 & $10,945,983$ & 0.055 \\
\hline
\end{tabular}

Table 9. Fatigue data for the roller PSV4 133315 from [38].

\begin{tabular}{cccccc}
\hline Samples & & Load $[\mathbf{K g}]$ & RPM & Cycles & SED [MJ/mm $\left.\mathbf{m}^{\mathbf{3}}\right]$ \\
\hline PSV4 133 315 & 1 & 1700 & 617 & 110,000 & 0.442 \\
& 2 & 1675 & 617 & 155,500 & 0.429 \\
& 3 & 1245 & 643 & $1,680,000$ & 0.237 \\
& 4 & 1245 & 643 & 521,658 & 0.237 \\
& 5 & 813 & 638 & $3,687,621$ & 0.101 \\
& 6 & 786 & 638 & $13,484,745$ & 0.094 \\
& 7 & 760 & 638 & $10,728,361$ & 0.088 \\
& 8 & 752 & 638 & $10,685,583$ & 0.086 \\
9 & 713 & 638 & $1,044,041$ & 0.078 \\
& 10 & 647 & 638 & $10,164,948$ & 0.064 \\
& 11 & 610 & 638 & $11,055,235$ & 0.057 \\
12 & 553 & 646 & $10,479,312$ & 0.047 \\
13 & 510 & 646 & $10,615,367$ & 0.040 \\
14 & 404 & 646 & $11,446,934$ & 0.025 \\
\hline
\end{tabular}




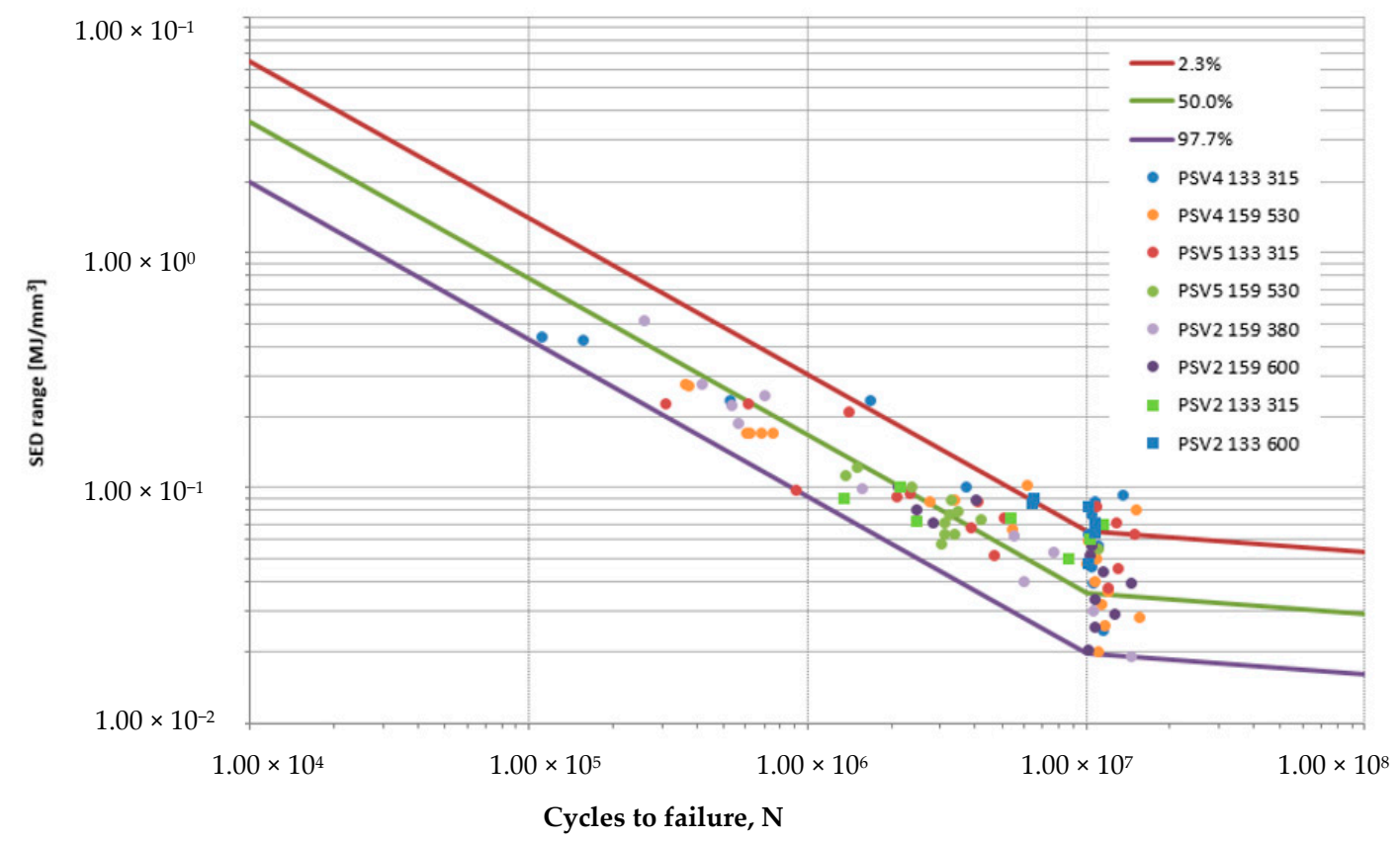

Figure 6. Synthesis of fatigue data for different roller geometries in terms of local SED and a comparison with the scatter band shown in Figure 1.

\section{Conclusions}

The SED approach has been herein used to assess the fatigue behavior of different types of PSV rollers, representing the state of the art of Rulmeca's production. These rollers are subjected to fatigue failures because of a lack of penetration of the weld root connecting the bearing housings to the tube body. Fatigue tests on seven different roller geometries have been carried out and the results have been analyzed in terms of SED. Together with the data obtained in Ref. [38], they have been reported to fall within the scatter band $\Delta \mathrm{W}-\mathrm{N}$ (strain energy range-number of cycles to failure) obtained in Ref. [21] that summarizes about 900 fatigue data obtained from welded joints characterized by different main plate thicknesses, different transverse plates, and different bead flanks. Although this scatter band was obtained with the majority of the failures occurring at the weld toes, it provides reliable predictions of the fatigue behavior of welded joints with failures from the notch root; i.e., the considered roller geometries.

Author Contributions: F.C. performed the experimental tests and analyzed the data; M.P. wrote the manuscript and partially analyzed the data; L.M.V. partially wrote the manuscript; F.B. and T.W. provided scientific guidance.

Funding: This research received no external funding.

Conflicts of Interest: The authors declare no conflict of interest.

\section{References}

1. Liu, H.; Wang, P.; Wei, X.; Xiao, J.; Chen, R. Longitudinal Seismic Response of Continuously Welded Track on Railway Arch Bridges. Appl. Sci. 2018, 8, 775. [CrossRef]

2. Stadler, M.; Freton, P.; Gonzalez, J.-J. Influence of Welding Parameters on the Weld Pool Dimensions and Shape in a TIG Configuration. Appl. Sci. 2017, 7, 373. [CrossRef]

3. Jin, L.; Xue, J.; Zhang, Z.; Hu, Y. Effects of Thermal Frequency on Microstructures, Mechanical and Corrosion Properties of AA6061 Joints. Appl. Sci. 2018, 8, 540. [CrossRef]

4. Ikram, A.; Chung, H. The Effect of EN Ratio and Current on Microstructural and Mechanical Properties of Weld Joined by AC-GMAW on Square Groove Butt Joints. Appl. Sci. 2017, 7, 261. [CrossRef] 
5. Schijve, J. Fatigue of Welded Joints. In Fatigue of Structures and Materials; Springer: Dordrecht, The Netherlands, 2009; pp. 535-558.

6. Atzori, B.; Lazzarin, P.; Meneghetti, G. Fatigue strength assessment of welded joints: From the integration of Paris' law to a synthesis based on the notch stress intensity factors of the uncracked geometries. Eng. Fract. Mech. 2008, 75, 364-378. [CrossRef]

7. Peron, M.; Razavi, S.M.J.; Berto, F.; Torgersen, J. Notch stress intensity factor under mixed mode loadings: An overview of recent advanced methods for rapid calculation. Fract. Integr. Struct. 2017, 42, 196-204.

8. Ferro, P.; Peron, M.; Razavi, S.M.J.; Berto, F.; Torgersen, J. The fatigue behavior of V-notches in presence of residual stresses: Recent developments and future outcomes. Fract. Integr. Struct. 2017, 42, 189-195.

9. Dunn, M.L.; Suwito, W.; Cunningham, S.; May, C.W. Fracture initiation at sharp notches under mode I, mode II, and mild mixed mode loading. Int. J. Fract. 1997, 84, 367-381. [CrossRef]

10. Dunn, M.L.; Suwito, W.; Cunningham, S. Fracture initiation at sharp notches: Correlation using critical stress intensities. Int. J. Solids Struct. 1997, 34, 3873-3883. [CrossRef]

11. Berto, F.; Lazzarin, P. Recent developments in brittle and quasi-brittle failure assessment of engineering materials by means of local approaches. Mater. Sci. Eng. R 2014, 75, 1-48. [CrossRef]

12. Ferro, P. The local strain energy density approach applied to pre-stressed components subjected to cyclic load. Fatigue Fract. Eng. Mater. Struct. 2014, 37, 1268-1280. [CrossRef]

13. Radaj, D. State-of-the-art review on the local strain energy density concept and its relation to the J-integral and peak stress method. Fatigue Fract. Eng. Mater. Struct. 2015, 38, 2-28. [CrossRef]

14. Radaj, D. State-of-the-art review on extended stress intensity factor concepts. Fatigue Fract. Eng. Mater. Struct. 2014, 37, 1-28. [CrossRef]

15. Lassen, T. The Effect of the Welding Process on the Fatigue Crack Growth. Weld J. 1990, 69, 75-81.

16. Singh, P.J.; Guha, B.; Achar, D.R. Fatigue life improvement of AISI 304L cruciform welded joints by cryogenic treatment. Eng. Fail. Anal. 2003, 10, 1-12. [CrossRef]

17. Singh, P.J.; Achar, D.R.; Guha, B.; Nordberg, H. Fatigue life prediction of gas tungsten arc welded AISI 304L cruciform joints with different LOP sizes. Int. J. Fatigue 2003, 25, 1-7. [CrossRef]

18. Williams, M.L. Stress singularities resulting from various boundary conditions in angular corners on plates in extension. J. Appl. Mech. 1952, 19, 526-528.

19. Lazzarin, P.; Zambardi, R. A finite-volume-energy based approach to predict the static and fatigue behavior of components with sharp V-shaped notches. Int. J. Fract. 2001, 112, 275-298. [CrossRef]

20. Livieri, P.; Lazzarin, P. Fatigue strength of steel and aluminium welded joints based on generalised stress intensity factors and local strain energy values. Int. J. Fract. 2005, 133, 247-276. [CrossRef]

21. Berto, F.; Lazzarin, P. A review of the volume-based strain energy density approach applied to V-notches and welded structures. Theor. Appl. Fract. Mech. 2009, 52, 183-194. [CrossRef]

22. Berto, F.; Lazzarin, P. Fatigue strength of structural components under multi-axial loading in terms of local energy density averaged on a control volume. Int. J. Fatigue 2011, 33, 1055-1065. [CrossRef]

23. Lazzarin, P.; Sonsino, C.M.; Zambardi, R. A notch stress intensity approach to assess the multiaxial fatigue strength of welded tube-to-flange joints subjected to combined loadings. Fatigue Fract. Eng. Mater. Struct. 2004, 27, 127-140. [CrossRef]

24. Peron, M.; Torgersen, J.; Berto, F. Rupture Predictions of Notched Ti-6Al-4V Using Local Approaches. Materials 2018, 11, 663. [CrossRef] [PubMed]

25. Razavi, S.M.J.; Peron, M.; Torgersen, J.; Berto, F.; Welo, T. 40CrMoV13.9 notched specimens under multiaxial fatigue: An overview of recent results. Fract. Integr. Struct. 2017, 41, 440-446.

26. Razavi, S.M.J.; Peron, M.; Torgersen, J.; Berto, F.; Mutignani, F. Effect of hot dip galvanization on the fatigue strength of steel bolted connections. Fract. Integr. Struct. 2017, 41, 432-439.

27. Gallo, P.; Razavi, S.M.J.; Peron, M.; Torgersen, J.; Berto, F. Creep behavior of V-notched components. Fract. Integr. Struct. 2017, 41, 456-463.

28. Razavi, S.M.J.; Peron, M.; Mutignani, F.; Torgersen, J.; Berto, F. Fatigue Strength of Hot-Dip Galvanized Welded Steel Connections. Key Eng. Mater. 2017, 754, 244-247. [CrossRef]

29. Peron, M.; Razavi, S.M.J.; Berto, F.; Torgersen, J.; Colussi, M. Fracture assessment of magnetostrictive materials. Fract. Integr. Struct. 2017, 42, 223-230.

30. Campagnolo, A.; Razavi, S.M.J.; Peron, M.; Torgersen, J.; Berto, F. Mode II brittle fracture: Recent developments. Fract. Integr. Struct. 2017, 42, 181-188. 
31. Peron, M.; Razavi, S.M.J.; Berto, F.; Torgersen, J.; Mutignani, F. Local strain energy density for the fatigue assessment of hot dip galvanized welded joints: Some recent outcomes. Fract. Integr. Struct. 2017, 42, $205-213$.

32. Razavi, S.M.J.; Peron, M.; Mutignani, F.; Torgersen, J.; Berto, F. A Study on the Fatigue Behavior of Hot Dip Galvanized Steel Connections. Key Eng. Mater. 2017, 754, 241-243. [CrossRef]

33. Peron, M.; Razavi, S.; Torgersen, J.; Berto, F. Fracture Assessment of PEEK under Static Loading by Means of the Local Strain Energy Density. Materials 2017, 10, 14-23.

34. Peron, M.; Razavi, S.M.J.; Berto, F.; Torgersen, J.; Marsavina, L. Local strain energy density for the fracture assessment of polyurethane specimens weakened by notches of different shape. Fract. Integr. Struct. 2017, 42, 214-222.

35. Berto, F.; Cendon, D.A.; Lazzarin, P.; Elices, M. Fracture behaviour of notched round bars made of PMMA subjected to torsion at $-60^{\circ} \mathrm{C}$. Eng. Fract. Mech. 2013, 102, 271-287. [CrossRef]

36. Razavi, S.M.J.; Peron, M.; Torgersen, J.; Berto, F. Static Multiaxial Fracture Behavior of Graphite Components: A Review of Recent Results. Key Eng. Mater. 2017, 754, 35-38. [CrossRef]

37. Razavi, S.M.J.; Peron, M.; Torgersen, J.; Berto, F. Notched graphite under multiaxial loading. Fract. Integr. Struct. 2017, 41, 424-431.

38. Berto, F.; Campagnolo, A.; Chebat, F.; Cincera, M.; Santini, M. Fatigue strength of steel rollers with failure occurring at the weld root based on the local strain energy values: Modelling and fatigue assessment. Int. J. Fatigue 2016, 82, 643-657. [CrossRef]

39. Seki, M.; Nishie, N.; Kozai, S.; Kakuda, M.; Soyama, H.; Naito, A.; Fujii, M. Fatigue Strength of Steel Rollers and Gears Treated by Cavitation Peening with Short Processing Time (A Case of Processing Time of $1 \mathrm{~min}$ and $5 \mathrm{~min}$ ). J. Adv. Mech. Des. Syst. Manuf. 2012, 6, 33-43. [CrossRef]

40. Fujita, K.; Yoshida, A. Surface fatigue failure of nitride-hardened aluminium-chromium-molybdenum steel rollers under pure rolling and sliding-rolling contacts. Wear 1979, 53, 61-68. [CrossRef]

41. Lazzarin, P.; Livieri, P. Notch stress intensity factors and fatigue strength of aluminium and steel welded joints. Int. J. Fatigue 2001, 23, 225-232. [CrossRef]

42. Taylor, D.; Barrett, N.; Lucano, G. Some new methods for predicting fatigue in welded joints. Int. J. Fatigue 2002, 24, 509-518. [CrossRef]

(c) 2018 by the authors. Licensee MDPI, Basel, Switzerland. This article is an open access article distributed under the terms and conditions of the Creative Commons Attribution (CC BY) license (http://creativecommons.org/licenses/by/4.0/). 